\title{
Excavating Longue Durée Histories of Food Security in Africa
}

One of this book's central arguments is that the scarcity slot is constructed and recursively maintained by an apparent scarcity of source material about past foodways. Fairhead and Leach's (1996) field-defining book Misreading the African Landscape provides one of the best examples of how the perceived scarcity of sources about West African pasts is an opportunity to bolster stereotypes about African environmental practices. They document how colonial and later administrators and policy-makers interpreted the presence of forest islands as a relic of a once more extensively forested landscape that had been degraded by African farming practices. Through comparing multiple quantitative and qualitative sources, Fairhead and Leach (1996) demonstrate that forest islands were instead created by Africans through generations of careful land management of savannas that would otherwise have lacked such biodiversity. They argue that administrators have essentially read land use history backwards, as indicating deforestation rather than the creation of forest.

Inspired by Fairhead and Leach's approach, I argue that we need to assemble a constellation of sources and methods in order to build longue durée histories of African food security. Historians and archaeologists have focused on related and causal issues like agriculture, poverty, development, health, and nutrition, but for the most part, this literature has not been directly marshaled to address the history of food security in the continent (with some important exceptions, e.g., Mandala 2005; Watts 2013). In this chapter, my goal is to bring some of these literatures together in order to advance a set of questions and approaches for conducting a longue durée history of food security. I first define food security and discuss how its changing definitions and approaches are relevant to Africa in particular. I briefly outline some of the intellectual influences on the study of the history of food security in Africa. I then explore a number of arguments drawn from archaeology, 
history, economic history, and anthropology that hint at major changes in African food security while at the same time exposing more questions than answers. In the final section, I detail the methodological approach I take in this book.

\section{DEFINING FOOD SECURITY AND SCARCITY}

Concern over having enough of the right food to eat at the right times is older than the human lineage-all organisms structure their lives and activities around the quest to acquire the nutrients and calories necessary for survival. Since Thomas Malthus's highly influential work An Essay on the Principle of Population (1798), experts have directed attention to the relationship between the human population and food supplies. Malthus reasoned that population increased geometrically, but that food supplies increased only arithmetically, and concluded that it was inevitable that population would eventually outstrip food supply. When this happened, food shortages, including famine, would reset the balance. He focused particularly on limiting population growth among the poor as a means to prevent wide-scale food scarcity. Though many of his main tenets have received considerable criticism in the last two centuries (e.g., see Devereux 2001; Maxwell 2001), his work continues to have powerful implications, and its main tenets are often subsumed implicitly into how we think about the relationship about food and population growth.

Boserup (1965) leveled an important critique at Malthus's reasoning, showing that in cases of population pressure, people often find ways to increase agricultural production. This has certainly been true of the last half of the twentieth century, in which the tenets of industrialization have been applied to agriculture on a massive scale. Yet the fear that populations will outstrip food supply remains one of the central rallying cries of private and public attempts to increase future food supply. Beginning in the 1960s, neo-Malthusians added the possibility of environmental degradation to Malthus's formulation. Namely, they note that agriculture may produce diminishing returns in situations where soil, for example, has been exhausted. Concern with climate change in recent decades has meant a return to neo-Malthusian ideas, which link environmental degradation to decreased food supply. Since the 1950s, a focus on "resources" has come to replace one on "scarcity," but concern about short supply remains central.

In all of these cases, a lack of food supply, whether caused by population growth or environmental deterioration or climate change, is considered to be the primary source of food insecurity. Yet in the late 1970 s and early 1980 s, researchers pointed out that food distribution systems are often more critical than food supply to insuring food security. Nobel laureate Amartya Sen's landmark (1981) Poverty and Famines argued that food crises are associated with a lack of entitlements (cash, labor, land, etc.) that insure access to food. His argument analyzed historical famines in India and concluded that food supplies during these times were more 
than sufficient. But the most vulnerable did not have the means to access those foodstuffs, since prices skyrocketed during periods of high demand as colonial officials continued to export grain.

In recent decades, famine analysts have critiqued Sen's overreliance on economic explanations and highlighted the structural, historical processes that create vulnerabilities. They acknowledge political agency as one of the primary causes of famine, shifting blame from nonhuman actors (drought, economies) to agents who might benefit from food crises (see Baro and Deubel 2006; Keen 1994). Other scholars have pointed out that an emphasis on severe and rare events like famines makes it seem as if food insecurity is unusual rather than the product of already existing vulnerabilities (Hendrie 1997; Watts 2013). Rather, they argue, famine is a worst-case manifestation of chronic food insecurity and poverty that leave people vulnerable to environmental, political, or economic shocks.

As a consequence of these and other critiques, there has been an important shift towards measuring and defining access to food rather than simply its availability. Analysts now focus on the household, rather than the nation, as the unit of analysis, which allows a more nuanced view of inequality across space. They also take into account a number of quantitative and qualitative variables_like height/ weight, livelihood, and degree of reliance on coping mechanisms - that permit a more specific examination of household food security and vulnerability (Devereux and Maxwell 2001; see also Wutich and Brewis 2014). Some of these measures are possible for past populations as well, including height and other biometric data from historical and bioarchaeological analyses, household and regional economic data, as well as plant and animal data that speak to coping mechanisms (see Nelson et al. 2016).

However, quantitative metrics do not always adequate capture the perception of hunger, which strongly informs people's actions and feelings of well-being. Quantitative analyses tend to privilege Western, scientific concepts of nutrition and food security over those of local populations who may evaluate hunger and scarcity in very different ways. Consider the two quotes that opened the introduction to this volume, from anthropologist Audrey Richards and environmental historian Alfred Crosby. To Richards, scarcity was in the eye of the beholder. The scene she describes makes clear that the Bemba considered maize as less than food, incapable of filling them up, whereas millet porridge provided true sustenance. Scarcity to the Bemba was experienced as a lack of preferred food, rather than a lack of calories altogether. Juxtapose Richards's take on scarcity against that of Crosby, who might define scarcity on the basis of food production. Crosby wrote at the height of the late 1960s-early 1970s Sahelian famine, when severe drought and unstable governments led to one of the most deadly food crises of the twentieth century. During this era, modernist development experts focused on increasing global food production as a means to insure such famines did not recur. Scarcity, in this view, was something that could be calculated quantitatively, based largely 
on agricultural production. This national-scale calories-in-calories-out equation is very different than the equation recognized by Richards among the Bemba, of scarcity based on preference. While Crosby's goals were very different than those of the food security analysts discussed here, my point is that we all operate with explicit or implicit ideas of what constitutes and causes food security or scarcity, and these strongly influence the narratives we tell about African foodways.

As Richards's Bemba example demonstrates, the ability to access preferred foods plays a major role in perceptions of scarcity. Scarcity is a feeling of deprivation, whether experienced as physiological hunger pangs or a psychosocially defined deficit. Scarcity is not an absolute lack of resources, but is always defined relative to human activity or social provisioning (Daoud 2010, 1207). Merriam-Webster incorporates both aspects, defining scarcity as "a very short supply; the quality or state of being scarce; especially want of provisions for the support of life." Notice here the incorporation of both a measurable definition, based on quantity or supply, and a more qualitative understanding referring to the state of being scarce or in want. The definition of scarcity used by Merriam-Webster is close to the one I use in this book, because it highlights both quantitative and qualitative aspects, and because these two definitions are often linked. A lack of food resources can easily manifest in feelings of deprivation; the former is often the proximate cause of the latter. But we have to look beyond proximate causation to the structural problems that cause some people to lack resources, if we wish to truly understand scarcity in both guises (Ribot 2014).

Food security is "when all people, at all times, have physical, social, and economic access to sufficient, safe, and nutritious food that meets their food preferences and dietary needs for an active and healthy life" (World Food Summit 1996; see Maxwell 2001 for an overview of the history of the concept). This holistic definition is the one adopted in this book, because it includes attention to multiple aspects or pillars of food security: availability, access, and preference. Availability relates in part to the modernist idea of scarcity, tracking the absolute and quantifiable number of calories produced and available to the populace. Access relates most closely to food distribution, which was the center of Amartya Sen's important intervention and its later refinements. And preference maps onto the kind of scarcity that Audrey Richards calls attention to, the perception of lack because you are unable to eat culturally acceptable or preferred foods. In previous publications (Logan 2016a, 2016b) and throughout this book, I have worked to trace these three constructs. Analyzing how they have changed over time in one small region serves as a backbone to my understanding of scarcity and food security in the archaeological record. My approach differs from that of other archaeologists who study food security (e.g., Nelson et al. 2016) in that I rely on both quantitative and qualitative data, as well as a deep engagement with local historical and ethnographic contexts (see below). ${ }^{1}$ In the next section, I explore some of the major themes within and limits to our understanding of African food security and its 
history writ large. By drawing on qualitative and quantitative studies on related topics like poverty and agriculture, I flesh out a more culturally specific method of exploring food history over time.

\section{THE INTELLECTUAL INGREDIENTS OF A HISTORY OF FOOD SECURITY}

Currently we lack a specific body of scholarship on the history of food security in Africa. But Africanist archaeologists, historians, and geographers have been adept at tracing the closely related topics of agriculture, environment, poverty, and to a lesser extent, food. My work builds on insights from these studies and attempts to combine them to advance an approach to the long-term history of African food security.

Agriculture in particular has received the lion's share of attention because of its central role in colonial and postcolonial African economies. In particular, the so-called agrarian question, whether and how African economies could transition from predominantly agricultural to industrial economies, subsumed much attention in political economy and ecology (see Moyo, Jha, and Yeros 2013), and necessarily focused scholars on production rather than food access or preference. For some scholars, particularly for political ecologist Michael Watts (1983 [2013]), studying famine and food production led to the realization that food distribution and access are among the most critical determinants of hunger. Watts (2013) argued that the incorporation of peasants into global market economies made them much more vulnerable to climatic shifts. His work is a strong influence on interpretations I raise later in this volume, since he deftly uses history to inform our present understandings of food security.

Several authors have responded to stereotypes about African agriculture as backward, with Richards (1985) for example instead demonstrating that farmers actively manipulated their farms to manage risk. A similar preoccupation with overturning assumptions about African environmental management dominated much of the environmental history literature in the 1990s, with Fairhead and Leach's contribution one of the most impactful in terms of policy (see also McCann 1999). Cumulatively, these works push back against the first and second tenets of the scarcity slot-that Africans could not produce enough food and were incapable of modifying their hostile environments-yet for some reason these tenets continue to be maintained, especially in food security and food history literatures. The tenacity of these views can be partly explained by the lack of a dedicated history of food security that explores the complex interplay of food availability, access, and preference over time. This book attempts to provide that, with a focus on the long-term that helps not only to combat the idea that African foodways are timeless, but also to reimagine different futures based on past accomplishments. Archaeologists have demonstrated many of these capabilities by documenting 
the independent invention of agriculture in the African continent, overturning decades of colonial ideology that assumed all inventions came from elsewhere (Marshall and Hildebrand 2002; Neumann 2005).

Agriculture continued to dominate the attention of environmentally minded historians, geographers, and anthropologists in the postmodern heyday of the 1990 s and early 2000 , but with an increased focus on identity issues with the rise of social history. Many of these studies emphasized the cultural specificities of agricultural practices and their meanings (e.g., Fields-Black 2008; Hawthorne 2003). Several scholars deployed innovative techniques to understand aspects of history, like local perceptions of abundance and scarcity, that have often fallen outside of the historian's gaze, as well as to delve into longer-term histories of agriculture in specific regions. Historical linguistics has proved an exemplar in both respects (e.g., de Luna 2016; Ehret 2014; Schoenbrun 1998; Stephens 2016, 2018a, 2018b). Social history approaches are essential to understanding some of the more qualitative aspects of food security, particularly food preference. Narrative plays a major role in how these scholars are able to broach social history, and informs my writing style and approach in this book.

Food history is still what we might call an emergent field in Africa, despite the meteoric rise of food studies and food history in recent decades. In part, this relates to a lack of traditional source materials like recipes, cookbooks, and written archives as compared with other world regions. I suspect the paucity of attention paid to Africa is also a function of the common misconception that people struggling with food insecurity have little choice over what they are eating (e.g., Van Esterik 2006). Works like James McCann's (2009) Stirring the Pot and Carney and Rosomoff's (2009) In the Shadow of Slavery have helped put African food history on the map, and have attempted to dispel this stereotype by presenting African cooks and farmers as skilled and strategic actors, particularly in the Atlantic exchange (see also Carney 2001; La Fleur 2012). Yet in most food studies scholarship, food security is rarely addressed or critically engaged. This divide is one I try to bridge throughout this book.

Another related trend is histories of poverty, both by economic historians (see below) and by social historians (Iliffe 1987; Stephens 2016, 2018a, 2018b). While few studies in this vein directly engage food (but see Bonnecase 2018), their findings are generally applicable to understanding shifts in poverty and thus food access over time and space. Rich conceptual histories of wealth and abundance are also relevant here for outlining not only the specific manifestations of these concepts in different groups and over time (e.g., Schoenbrun 1998; Stephens 2016), but also their implications for food security. In short, the intellectual ingredients for a history of food security in Africa are already present. In the next section, I consider some of the changes in food security over time that we can deduce based on these studies. The spatial and temporal coverage of relevant studies is patchy. I want to stress that my intent is not to make a pan-African argument for changes 
in food security, but instead to illustrate the major shifts suggested by the available data. I argue that we need to evaluate these potential shifts in food security by building empirical histories of food security, and I conclude this chapter with a consideration of the methods for doing so.

\section{SHIFTS IN FOOD AVAILABILITY AND ACCESS IN AFRICA'S PAST}

Combined, these diverse bodies of research hint at major shifts in the productive capacity of African agriculture and document the agility of farmers over the last five millennia and more. While a continent-scale review of all of these changes is beyond the scope of this chapter, I briefly mention several shifts to foreground the Banda case study in wider context, and to provoke a series of initial questions that we might ask of a longue durée history of food security in Banda and more broadly.

Most archaeologists interested in African agriculture have focused on its emergence between ten thousand and three thousand years ago-a key transition in the productive capacity of many groups that has implications for food security, though it is earlier than the time frame covered in this book. ${ }^{2}$ Although transitions like this that occurred in deep antiquity may seem to have little relevance for modern agriculture, some of the big-picture findings about this period demonstrate the importance of a longue durée view of agriculture and food security. For example, unlike in some world regions, where agriculture largely supplanted hunting and gathering strategies, case studies from across the continent indicate that people continued to use wild animals and plants alongside domesticated varieties for a considerable time, and that many people preferred to continue foraging as a primary subsistence strategy (e.g., de Luna 2016; Neumann 2005). Marshall and Hildebrand (2002) suggest that early domestication was motivated by a desire to reduce risk, a concern that motivates more recent farmers as well (Richards 1985). By the start of the common era, people living in more aggregated towns and cities showed various subsistence specializations, from farming to fishing to hunting (McIntosh 2005), a tendency which also reappears in later societies and probably has a very ancient origin (cf. Ehret 2014).

In considering shifts in productive capacity, we would do well to note strategies like risk reduction and specialization that reoccur in African food systems, not because their continued presence suggests that agriculture is unchanging, but because it suggests a deep reservoir of historical knowledge that can be accessed when people face problems similar to those of the past (cf. Moore and Vaughn 1994). ${ }^{3}$ These recursive problems and solutions may be at odds with the narrow focus of many Western scientists on overproduction in the pursuit of surplus. Most classic models of agricultural origins focus on this as a universal goal (see de Luna's [2016] excellent critique of this concept in regard to African hunter-gatherers). Agricultural systems have periods of boom (harvest) and bust (just before 
harvest) that require storage throughout the year. For some crops and areas of the world, the ideal is to store as much as possible, in order to get people through the bust season as well as through a bad year or two of harvest. Storage also leads to the potential for accumulation of surplus by individuals or groups, who can then restrict food access for more vulnerable groups. Most attention to this dynamic has been devoted to studying the often large, well-organized agricultural systems of hierarchical societies. However, many of these same societies are also characterized by high levels of inequality, which can lead to differences in food access. Archaeologists have observed that African case studies rarely have the characteristics of a classic hierarchical state, instead suggesting more heterarchical organization, in which multiple interacting parts may or may not have power over other segments or groups (e.g., McIntosh 1999). Ensuring more equitable food access may have been politically advantageous in heterarchical systems, though we must not assume that egalitarian ethics defined political relationships for all Africans at all times (cf. Stephens 2018b, 403).

Archaeologists have also attended to the agriculture of the so-called Iron Age societies of the last two to three millennia, a time during which agriculture spread, people developed a wider array of crops and elaborated and intensified agricultural systems in sub-Saharan Africa (Neumann 2005). The success of these agricultural regimes is suggested by the emergence of the state-level societies and/or dense urban populations recorded in the Horn of Africa (e.g., Meroe and Aksum; see McCann 1999, 36-47), the Swahili Coast (LaViolette and WynneJones 2018), the Great Lakes (Robertshaw 1994; Schoenbrun 1998), southern Africa (e.g., Mapungubwe and Great Zimbabwe; see Pikirayi 2002; Huffman 1996), and West Africa (e.g., Ile-Ife and Jenne-Jeno; see McIntosh and McIntosh 1981, 1984). With the exception of the Swahili coast, which came to rely on Asian rice (Walshaw 2010), each of these polities was supported by indigenous African crops like pearl millet, finger millet, sorghum, and yams, as well as livestock including cattle, sheep, and goats. Arabic chronicles of the trading empires along the Niger River provide compelling documentation for the region's surplus production of agricultural goods (Lewicki 1974; chapter 3). Where environmental records are available for comparison, it appears that some of these societies also demonstrated a high degree of resilience to climatic amelioration (McIntosh 2005). In other societies where drought seem to have had a more significant impact, social pressures seem to have also played an important causal role in their decline (Huffman 1996; Pikirayi 2006; Taylor, Robertshaw, and Marchant 2000). The emerging picture, then, is that during this period African crops and livestock enabled dense populations and a degree of resilience to environmental change, at least in the regions cited above. While these findings hint at the possibility that these societies maintained high food security, food-related data are not available for most of these areas at present (important exceptions are Murray 2005 for Jenne-Jeno and Walshaw 2010 for Swahili). Future studies might investigate whether food was 
distributed equally among constituents of these politically centralized societies, as well as the strategies people used to produce and access food during environmental and economic shifts.

Despite a profusion of archaeology devoted to the study of the last five hundred years, few archaeologists have focused on agriculture during this period, largely ceding the topic to historians (see Gallagher's 2016 review), though this appears to be changing in recent years (e.g., Gijanto and Walshaw 2014; Logan and Cruz 2014; Logan 2016a, 2016b; Monroe and Janzen 2014; Walshaw 2010). There is considerable need for archaeological and linguistic study of the movement and roles of plants and animals during this period. What Africans actually did and the decisions they made, especially on their farms or in their kitchens, were often very different than the views accessible to European observers. This is significant, since many disciplines rely on European and colonial records not only to understand the colonial period but also to project these dynamics back onto the precolonial past (chapters 3 and 4 ).

The arrival and adoption of American crops, especially maize and cassava, has received the most attention, since these crops are thought to have improved the productive capacity of African agriculture due to their short maturity time (maize) and ability to grow on poor soils with less labor (cassava). Given the presumed importance of this shift, it is surprising how few archaeological data are available on the topic (Gallagher 2016). Understanding this process is necessary for evaluating the capabilities of African agriculture prior to European interventions. As detailed in chapters 2 and 3, American crops took centuries to become staples in Banda. We find a similar hesitancy to abandon local crops in almost all cases where systematic recovery and analysis of plant remains has been pursued (Gijanto and Walshaw 2014; Esterhuysen and Hardwick 2017; Widgren et al. 2016), an important distinction since maize presence is often inferred indirectly (e.g., see review in Widgren et al. 2016). This finding is at odds with the historical literature, which focuses on coastal enclaves (e.g., Alpern 1992, 2008; La Fleur 2012; McCann 2005), where agricultural production was often geared towards the provisioning of European trade ships (Carney and Rosomoff 2009). Two recent books on the adoption of American crops on the West African coast argue for considerable African agency and ingenuity in the use and production of these new foods (Carney and Rosomoff 2009; La Fleur 2012). These are exceptional contributions to a literature dominated by Crosby-influenced interpretations of the Columbian Exchange (see chapter 2), and they provoke a series of questions about the relative roles of indigenous and introduced crops as well as about the food security of African societies during the Atlantic era.

In addition to revealing much about successful agricultural strategies in the past, findings like these are important because they can inform recent attempts by economic historians to quantify agricultural production in Africa in precolonial times. Many such studies note the poor productivity of African farms compared 
to those elsewhere in the world, since in these data land is generally plentiful but labor is often scarce, a ratio that favors extensification rather than intensification strategies. Coupled with environmental "limitations" like poor soils and restricted distribution of livestock, the result has been an agricultural system with low productivity per unit land (Hopkins 1973). This low productivity made it more profitable, according to some economic historians, to transport labor from the African tropics to the Americas, where agriculture was more productive (Austin 2007, 2008a). I take no issue with the general observation that lack of labor may result in lower agricultural productivity, a point I return to in chapter 4 . But there are some methodological concerns with the "timeless" application of this equation. Estimates of apparently low agricultural productivity in Africa are generally derived from colonial sources, which present imperfect records of production given that centuries of slave trading had forcibly removed generations of African men and women in their primes, depriving African farms of significant amounts of labor as well as skill (see chapters 3 and 4). So too must we be cautious of classifying all of the continent's diverse ecological niches as limited; as Schoenbrun (1998) artfully illustrates, some places offered abundant resources. The archaeological examples cited above suggest that agriculture was capable of supporting large, dense urban populations, and at the very least that low productivity did not define all times and places in the continent. The question then arises as to whether Africa's environment(s) are really the limiting factor in agricultural production, or whether political and historical factors also played and continue to play strong roles.

Historical research suggests that many parts of the continent have witnessed major economic and demographic shifts over the last five hundred years, with major implications for the ability to access food. Walter Rodney's (1972) How Europe Underdeveloped Africa blamed Europe's extractivist endeavors, especially the trans-Atlantic slave trade, for retarding economic and demographic growth in the continent. This argument implies a serious reduction in entitlements and consequently food security. More recently, Pomeranz (200o) postulated a Great Divergence, in which the so-called developed world experienced major leaps in economic growth in the nineteenth century, while other regions such as the African continent did not. Working with what is now known as the reversal of fortune (RF) hypothesis, Acemloglu and colleagues (2002) compared the economic development of non-European areas at two points in time: 1500 (via population density and urbanization) and 1995 (via GDP). They found that the parts of the world that were most developed in 1500 (Africa, South America) were among the poorest countries in 1995, whereas the areas that were poorest in 1500 (the Americas, Australia) were among the richest countries in 1995. They explain this divergence on the establishment of European institutions like private property rights, which tended to be strongest in regions with significant settler populations. Nunn (2008) elaborated the RF thesis by a specific consideration of Africa-side dynamics including the trans-Atlantic slave trade. 
The RF thesis has effectively energized a generation of economists and historians to revisit precolonial history and think about today's economic problems as results of change over the longue durée (e.g., see Akyeampong et al., 2014). However other economic historians have pointed out limitations of the thesis and the database on which it relies, particularly concerning the quality of the precolonial data (Austin 2008b; Hopkins 2009). Population density data are largely derived from colonial sources which are then adjusted for certain events (e.g., the slave trades) and projected back in time-a practice that experts consider highly problematic (Manning 2014). Further, Austin (2008b) notes that the decision to compare only two points in time-1500 and 1995-compresses the history of the intervening centuries. To these critiques, we might add concern about the use of patchy data to extrapolate continent-wide generalizations. Curiously, archaeologists remain largely unaware of the RF thesis despite the fact that our data sets are well equipped to address it. We regularly determine the size and density of settlements, and tend to focus on other kinds of relevant economic data on trade, for example, that would help refine or challenge some of the more problematic aspects of the RF thesis as well as provide texture and detail to these narratives at the regional level.

As with Rodney's argument, we could extend the RF thesis to postulate a major drop in food security between 1500 and the late twentieth century, since a decrease in economic well-being often results in food insecurity. I explore this argument throughout this book by examining the intervening centuries to draw out the regionally grounded long-term processes of disenfranchisement that are so far missing from the RF thesis (Green 2019). The Atlantic slave trade, which formed the central backbone of Rodney's (1972) argument for the underdevelopment of Africa, is one such process. Rodney argued that the Atlantic slave trade had resulted in stagnant population growth, especially in the eighteenth and nineteenth centuries. The implications for agriculture are clear-especially if one puts stock in the argument that labor has been the limiting factor for agricultural productivity in many parts of the continent. Carney and Rosomoff (2009) build on this and explicitly argue that the slave trade depopulated many regions of farmers in their primes, resulting in not only a labor deficit but also a brain drain. The timing proposed by these scholars appears to coincide with Banda's experience, as I explore in chapters 3 and 4 .

Still, when we look outwards to other case studies, the takeaway points are different. Focusing on Central Africa (especially the Kongo kingdom), Vansina (1990, 211-16) documents increasing demand for foodstuffs by European slaving vessels on the coast, which was met by increasing agricultural production of a new cultigen, cassava, and by establishing slave villages and farms. This finding supports the conclusion drawn by Carney and Rosomoff (2009) that American crops were well suited to the trade in human beings, since their production could be scaled up effectively. But other African polities, particularly those in the hinterlands, appear 
to have developed different strategies. For example, the political organization of some African polities, like the Sokoto caliphate, appears to have afforded high levels of food security for some regions during the upheavals of the nineteenth century (Watts 2013), although it is unclear whether or not everyone enjoyed equal access to food supplies (probably not, as Green's [2019] argument for increasing inequality suggests). These differences prompt important questions about the relationships between agricultural production, food security, and the slave tradesand their lasting consequences across diverse landscapes, some of which I take up in chapter 3 .

If our understanding of agricultural production in precolonial periods is limited to some degree by the paucity of data (Widgren 2017), we know comparatively much more about changes in agriculture during the colonial era. Increasing agricultural production was a central goal of most colonial administrations in the African continent, so there is a better archive for this period, with some important caveats. Most of the focus was on documenting the production and potential production of cash crops rather than subsistence crops. As Moore and Vaughan (1994) detail, farmers often strategically underreported their harvests or simply moved out from under the gaze of colonial officials. For this and many other reasons, Sara Berry (1993) argues that agricultural data for the African continent is woefully insufficient. This state of affairs makes it exceedingly difficult to evaluate the impact of colonial policies. Iliffe's (1987) continent-wide survey suggests that impacts were variable over time and space. One central concern revolves around the impact of cash-cropping, a strategy that most colonial administrations adopted to fund their African colonies (see Berry 1993). The cultivation of cash crops effectively siphoned land and labor away from the production of subsistence crops in the service of growing global commodities like palm oil, cocoa, and cotton (Mandala 2005; Watts 2013). In other contexts, colonial officials actively policed what they saw as wasteful agricultural techniques like slash and burn, which provoked a range of local responses (Moore and Vaughan 1994). For regions lacking cash crops, the impacts of colonial interventions are more slippery but not impossible to trace, as we will see in chapter 4.

The new science of nutrition emerged beginning in the 1930 s with the realization that inadequate food intake resulted in health problems, and that these relationships could be measured. Medical doctors in the colonial service were often tasked with documenting and identifying these relationships, and their reports provide a detailed glimpse into the health of the poorest colonial subjects in particular (Worboys 1988). Height data from military conscripts has also been used by economic historians as a proxy for nutrition, since height is dictated by protein intake in addition to genetics (e.g., Austin, Baten, and van Leeuwen 2012). Yet studies relying on these data would benefit from insight as to the context of this suffering, including the economic and social positionalities of the patients. 
Refining the method for understanding colonial food security is important not only because of what it reveals about food security during that period, but also because the colonial period is often used as a baseline to understand deeper, precolonial histories. Even Audrey Richards, who was interested in the changes induced by colonial policies, did not acknowledge the changes that occurred among the Bemba prior to the start of her fieldwork in the 1930s (Moore and Vaughan 1994). One of the main challenges is the source of the data itself: records created by colonial officers or scientists working for them. As Tilley (2011) has argued, colonial officials and scientists sometimes had the interests of their subjects at heart, and many documented the problems with colonial policies, particularly concerning agriculture (Moore and Vaughn 1994). However the pendulum also swung the other way, as we will see in chapter 4, when officials in the British Gold Coast actively suppressed the study of a medical doctor who found extreme levels of malnutrition in the Northern Territories, for fear it would generate negative press at home. This case demonstrates the importance of reading against the grain through using multiple archives, something that Africanist anthropologists, archaeologists, and historians have been remarkably adept at doing.

\section{EXCAVATING AFRICAN FOOD HISTORY}

In this book, I propose that we engage food security in Africa's past by focusing on its food history writ large. As McCann (2005) argues, a broader focus on food history acknowledges that food is about more than agronomic potential, and includes a range of tastes and textures produced by skilled cooks and enjoyed by people of all classes. Food history thus allows us to populate agricultural and environmental histories and to get a better understanding of food preference and desires. While many disciplines and associated methodologies have provided clues into African food history, there has been little explicit discussion of how we construct African food histories.

Two approaches have dominated studies of related topics in the past: the quantitative approaches of economic historians and food security analysts, and the more qualitative engagements with context of social and food historians. Economic historians prefer large, quantitative datasets that are used make comparisons between continents and time periods. They tend to test big ideas. The scale of their ideas and the influence of economics means that their conclusions spread more widely among academics and are more likely to inform policymakers, even if their application to specific settings is often inappropriate. There is a major danger in using examples from selected regions to formulate patterns about the continent as a whole, a practice that reifies the Africa-is-a-country stereotype. By contrast, historians and anthropologists largely rely on approaches that permit contextually sensitive portrayals that are more effective at investigating underlying 
causes and complications. However these narratives tend to be dense and specific, which limits their accessibility to scholars in other fields and to nonacademics.

I take particular insight from Fairhead and Leach's mixed-methods approach, because their study has been successful in rewriting narratives about African environmental practices and in reaching both academic and professional audiences. Like many environmental historians, they marshal empirical data drawn from environmental sciences, together with archival and ethnographic data that fleshes out cultural histories and contexts. They do so in an explicitly contrarian frame, seeking to overturn a specific stereotype about land degradation and its causes in Africa. In this book, I make use of empirical data derived from archaeology to reconstruct past food practices, as well as archival and ethnographic accounts that help add flesh to these empirical bones. I adopt a narrative framework that explicitly aims to challenge the central tenets of the scarcity slot, in an effort to produce a new narrative about food security and food history in Ghana, with implications for pursuing similar histories elsewhere in the continent.

What is also different about my approach is its coverage of the longue durée, from about 1400 to 2014. To capture this long time frame, I rely on the empirical databases and conceptual tools of archaeology. Archaeological data extends our timeline back almost indefinitely. As I will illustrate in subsequent chapters, scholars often read scarcity into past foodways because the data sources they consult are from much later in time, and thus from a different political and economic context than the period under study. This practice of baselining reifies the assumption that little has changed in regards to foodways, and reinforces the third tenet of the scarcity slot. Archaeologists anchor the timing of certain events, like the introduction of American crops, in chronological space that is for many regions beyond the reach of traditional documentary archives (but see La Fleur 2012 for an excellent use of documentary and linguistic sources in tracing the arrival of these crops on the Ghanaian coast). Archaeological chronologies often have ranges that are much coarser than the calendar dates of historians, since we tend to rely on radiocarbon dates that give a broader range (a date plus or minus a standard of error).

Archaeological data also reveal a different perspective on food than written archives. We study the material remains left behind as the results of people's past activities, decisions, and experiences, providing a ground-up view of everyday life (Robin 2013; Stahl 2001). The scale of this kind of history is ideal for tracing the kinds of things that McCann (2009) notes as so critical to unraveling African food history-women's knowledge, ingredients, and diversity of techniques. Historians have long made use of archaeological data to anchor certain events in time, but archaeology is usually supplementary to their main arguments (see also Robertshaw 2000; Vansina 1995) with the important exception of some historical linguists who demonstrate high proficiency in archaeology (de Luna and Fleisher 2019; Ehret 2002; Schoenbrun 1998). In this book, I make material data 
central because they are so well suited to revealing food history. Archaeology's ground-up perspective provides us with a unique scale from which to examine human history, one that avoids the problems of top-down history (see Stahl 2001). Material remains allow us to forefront human agency because we can trace what people actually did, rather than rely on what they say they did (as with historical linguistics) or what others said they did (as with most written archives) (see de Luna and Fleisher 2019).

This unique vantage provides us a sideways glance at received histories, making archaeology an especially critical toolkit for dismantling dominant assumptions like the scarcity slot. Žižek (2008) argues that in order to see pervasive structures and processes we need to observe and document them using a "sideways glance," an alternate viewpoint gleaned from different methods or starting assumptions. Food security is usually viewed from a presentist perspective, which limits the set of possibilities for the past and future and obscures the power relations at the heart of modern development. The longue durée view pursued in this book does important analytical work by revealing the historical processes that created present-day food insecurity but also by using the past as foil to the present. By sifting through the past, we are also able to evaluate what passes for common knowledge about African foodways.

Excavation is the primary method of field archaeology, and inspires my approach to African food history. Archaeologists excavate sites by carefully removing one layer of sediment at a time. That layer can be defined in various ways, usually by means of the natural or cultural stratigraphy (based on color and texture of the sediment), or of arbitrary levels (e.g., 10 centimeters) designated by the archaeologist. Ideally, each layer corresponds approximately to a period of time, although in practice this is often more complicated than it first appears. Nevertheless, each layer forms a basic unit of comparative analysis for archaeologists. Similarly, I divide Ghana's food history into rough periods, as presented in the next four chapters. ${ }^{4}$ Material remains from the same level are usually collected and interpreted together to form an argument about what was going on in that period. This is very important, because it insures that objects are interpreted relative to one another and to the context they come from, avoiding the problems of baselining discussed above. Results from each layer are then compared to those above and below it to generate information on trends over time.

In this book, the act of excavation is literal, as I have just described, as well as metaphorical. Metaphorically, it is necessary to peel back the layers of assumption that have built the idea of Africa as a scarce place. In each chapter, I present one or more interpretations that have defined our understanding of foodways in that period, and attempt to evaluate each one with empirical evidence from the same period. This simple methodology provides an appropriate framework for thinking about African food history, and in particular for debunking the scarcity slot. Excavation trains our focus on information drawn from the period in 
question. Wherever possible, I compare data that are coterminous-from the same period-rather than rely on analogies drawn from later time periods. In chapter 4, I show that the baseline most commonly used to approach African food history is drawn from the most food-insecure period in its recent history. In order to evaluate scarcity over time, we must be careful not to assume the insecurities of one period are applied to another.

Archaeologists typically compare the content of different layers with those above and below to generate an argument about change over time. This crossperiod comparison is critical to food history, because it relies on the comparison of contextually anchored narratives of one time period with those of other periods, rather than on baselining. It has often been assumed that foodways change slowly, but this is not always the case. People confronted with novelty (like American crops) or challenges (like declining household income) may make rapid changes to their diets (Macbeth and Lawry 1997). A cross-period comparison allows us to understand what came before as well as the rate and scale of changes over the longue durée. In some senses, this cross-period comparison is one of the most convincing parts of the RF hypotheses, yet comparing two distant chronological points (1500 and 1996) leads to the compression of history in intervening centuries (Austin 2008b). Archaeology adds more layers and in so doing makes historical processes visible.

The excavation method also provides a scaffolding for comparison that is rooted in a specific locality, answering the problems with lack of context that arise from large-scale comparisons such as the RF hypothesis. Archaeologists approach change over time by comparing layers in a multiscalar sampling universe. At the microscale, we can compare layers in an individual excavation unit of varying size (from 1x1 meter to squares of much larger sizes), which represents a small sample of the occupation of that area. Most often, we eventually scale up to the level of the archaeological site, which often approximate units like villages or towns that were culturally meaningful in the past. We also compare information among sites to arrive at regional historical trends. Archaeological units are always samples of a much larger universe. While some may see this as limiting the applicability of our results to national or global scales, in the case of food history such microhistories are important sources of alternative possibilities. In this book, I do not attempt to write a food narrative that applies to all of Africa; instead I offer a counternarrative from one small region in central Ghana that challenges the tropes of the scarcity slot. In so doing, I hope Banda can serve as a point of inspiration and comparison for the construction of other counternarratives on the continent. Where possible, I compare Banda to other parts of Ghana, which brings out some of the divergent responses to Atlantic trade and colonialism.

Excavation also relies on the careful sifting and collecting of material remains from their sedimentary contexts, and an acknowledgement of the affordances and taphonomic histories of those artifacts. ${ }^{5}$ It is impossible to construct a perfect 
history; we are bound by our archives as well as by the perspectives those archives communicate and silence (Trouillot 1995). In some cases, entire sets of activities or people may remain invisible. For example, in written records, women and their activities are often portrayed only in ephemeral ways, since most European chroniclers were men. Archaeology helps provide a solution, since material remains record the everyday activities of most people. But some activities have few surviving material traces; in terms of food, for example, we are hard pressed to find traces of ancient tuber crops like yams and cassava. Historical linguistics would greatly help in tracing these crops, as it has in other places in the continent, but is unavailable for Banda and surrounding areas. Instead, we are left to infer their use based on other kinds of material remains or on later records of their use. In these instances it is necessary not only to be clear about the source of this information, so that later scholars can offer critique if needed, but also to note that these arguments are less strong than those for which we have good material evidence. This kind of approach is very important for making sure we do not recreate new stereotypes while attempting to debunk the scarcity slot.

One of my primary sources of data about ancient foodways comes from archaeological plant remains. Archaeobotanists or paleoethnobotanists study three kinds of plant remains (macroremains, phytoliths, and starch grains) that come to be deposited and preserved in the archaeological record (Pearsall 2015). I rely mostly on macroremains-seeds, nut shells, and other plant parts-that are usually preserved in charred form. This means they must come into contact with fire in order to last long enough for archaeologists to recover them. Like any source of data, macrobotanical remains are subject to several preservation biases, but luckily cooking and processing activities are well represented in the remains (Hastorf 2017). Unfortunately, soft plant parts, especially tubers, are underrepresented, which limits my interpretations at times. I have tried to uncover these plants as well as activities that do not involve fire by also analyzing phytoliths. ${ }^{6}$ Phytoliths are distinctively shaped silica casts of plant cells or intracellular spaces that allow archaeobotanists to identify specific parts of a plant (leaf, seed, glume, etc.) as well as different plant taxa (Piperno 2006). Unlike better-researched areas of the world, where methodologies have been developed to identify specific plants, analyses are only in their infancy in the African continent and as such their applications are limited as of yet (see appendix A; Logan 2012, 82-116; Ball et al. 2016). When possible, I use phytolith analysis to flesh out how different grain crops were used, but future work will surely unleash a plethora of insights that are unavailable to us at present.

Archaeobotanical remains reveal the plant-based component of past diets, which forms most of what people eat; they are one of the most reliable means of accessing this part of the culinary past. However, in order to access their full interpretive value and flesh out political and cultural contexts we must compare plant remains with multiple other kinds of data. This present study is only possible 
because of over thirty-five years of sustained archaeological work at Banda, under the direction of Ann Stahl. Stahl and colleagues have documented the many other kinds of material remains that archaeologists encounter and that are important for constructing food history. These include ceramics, the vessels in which food is cooked, stored, and served; animal bones, the leftovers of meat and animal consumption; metals, ranging from everyday agricultural implements like iron hoes to specially fashioned copper alloy ritual objects; and a wide array of more rare items, like ivory and beads, which attest to vibrant and diverse local economies and ritual ecologies. These data are derived from archaeological excavations at villages that span the last one thousand years, and include intensive sampling of four major archaeological sites as well as regional sampling of many more, details of which can be found in Ann Stahl's comprehensive publications (e.g., Stahl 1999b, 2001, 2007) and are discussed in each chapter. Full methodological and sampling details can be found in appendices $A$ and $B$.

In chapters 2, 3, and 4, I put archaeological data directly into conversation with some of the primary arguments about the corresponding period. The scholars making these arguments come from a variety of disciplines, including history and geography, and some did their work long ago and in different intellectual climates. In most cases, these researchers had very little data on which to base their arguments, and so made logical leaps that were unfortunately based more on prevailing ideas about the African continent than on empirical data. I have selected these particular arguments not because they make easy straw men, but because they remain remarkably tenacious in how we think about African foodways. It is essential to critique each of these arguments head-on in order to change dominant narratives about African foodways and African history in general. Archaeological data not only provide an empirical test of these arguments, but also offer alternative narratives about the period in question.

For later time periods, particularly the nineteenth and twentieth centuries, I supplement archaeological information with historical and ethnographic archives, which add considerable texture and connect the material past to lived realities of the present. These chapters are critical in connecting past and present, a project that is central to the goals of this book. Yet I also acknowledge my limitations as a historian or cultural anthropologist. Interdisciplinary work requires that we go beyond our theoretical and methodological comfort zones, but one's strengths and weaknesses are bound to show in the cracks of arguments left unexplored and sources left unturned. I consulted archival sources at Ghana's National Archives in Accra as well as regional archival offices in Sunyani and Kumasi (appendix A). Secondary source material from the careful work of historians and archaeologists provides a check on the work I present here, and helps flesh out though not wholly eliminate the blind spots in my own archival work.

The ethnographic component of this work is captured in chapters 5 and 6, which focus on the last half-century or so. Most of this ethnographic study was 
conducted over a six-month period in 2009, followed by shorter six- to eightweek visits in 2011 and 2014. My primary goal was to understand the topography of food changes over the last few generations. I relied on semi-structured interviews supplemented by participant observation. In total, I was able to conduct 120 interviews with women and men spread over five villages with the assistance of Enoch Mensah, an exceptional research assistant and translator from Banda.? My focus was on women, since they are the primary cooks. A smaller number of men were interviewed regarding shifts in agricultural practices. While these data are sufficient to inform chapters 5 and 6 , the relatively short window in which they were collected precludes a more comprehensive monograph-length treatment. Consequently, the reader will see that these chapters focus quite narrowly on food and women's work over time. I acknowledge that the changes and continuities I observed were part of a much more complicated cultural tapestry that I was able to cover only superficially.

Whatever my limitations as an ethnographer or historian, I find value in being pulled into the present from the past. The narrative that results is what we might call an archaeological ethnography of food, in a similar vein as Lynn Meskell's (2011) archaeological ethnography focused on South Africa. My goals are to connect the past to the present in a meaningful way, and to use those connections to speak to possible futures. To me, this is the power of the archaeological ethnography genre. This genre also acknowledges the tremendous leaps that have been made by ethnoarchaeologists in the African continent, many of whom have transcended traditional ethnoarchaeological questions to ask more culturally appropriate and ethnographically informed questions and have become advocates for the communities in which they work (e.g., González-Ruibal 2008, 2014; Schmidt and Pikirayi 2016). I also take insights from the many attempts of Africanist archaeologists to make the past useful in the present (e.g., Lane 2015; MacEachern 2018; Stump 2010). This archaeological ethnography of food also follows in the footsteps of the work of many Africanist historical anthropologists who have combined multiple archives in attempts to provincialize hegemonic discourse about Africa's past (Comaroff and Comaroff 1991, 1992, 1997; Stahl 2001; Vansina 1990). In particular, these works have attended to the critical question of how knowledge about the past is produced, which is essential for unraveling food histories as well. My goal here is to make a similar intervention in our understanding of Africa's foodways past and present.

Writing an archaeological ethnography of food makes it necessary to communicate things a bit differently, and readers will find that this volume is neither a traditional archaeological monograph nor an ethnographic or historical one. One of my central goals is to make archaeological data accessible to the nonspecialist, because this is essential for advancing a new kind of African food history. I do not dwell on the limitations of archaeological data. No discipline has access to a perfect data set. While I am cautious in my interpretations, I avoid listing 
or evaluating the multiple sets of alternative hypotheses that may explain certain patterns in the main text. These are important, even critical, exercises, but have already been accomplished in other published work on Banda, most notably in the work of Ann Stahl as well as my previous publications. I have also removed the customary tables of material remains that tend to be found in archaeological works from the main text and instead have focused on offering qualitative descriptions. These data as well as the methods used to produce them are available in the appendices. Abandoning these two archaeological writing conventions means I am able to focus less on objects and data and more on human experience. Following the lead of Hegmon and colleagues (2016), wherever possible I make people, rather than material types, the subject of my argument. While the archaeological portions of this book do not completely match the ethnographic ones in tone, I do my best to make both speak to everyday life in the period of focus. 